\title{
POST B.C.G. ABSCESS IN AUSTRALIAN SERVICE CHILDREN
}

\author{
ANGELA OWEN-SMITH M.B., B.S., D.C.H. \\ C.M.P. Families Medical Centre, Terendak, Malaysia *
}

SUMMARY : Axillary and cervical abscesses following B.C.G. vaccination have occurred in the children of Australian servicemen in Malaysia and Singapore. This paper describes a series of such patients, their treatment and the investigation leading to the discovery of the probable cause of the abscesses.

Regional lymphadenopathy or abscess formation following B.C.G. (Bacille-CalmetteGuerin) vaccination against tuberculosis is unusual. When a number of such cases presented at Terendak Military Hospital, Malacca, Malaysia in the years 1967-1969 a special investigation was undertaken to study the problem. The hospital dealt with military personnel and their dependants mainly from 28 (Commonwealth) Infantry Brigade and other units of 17 (Gurkha) Division. Consequently the patients included British, Australian, New Zealand, Gurkha, Malay, Indian and Chinese military personnel and their families. It was noticed that although B.C.G. vaccination was performed on children of all racial groups in Terendak using Glaxo freeze dried vaccine, there were no complications other than minor localised persistant ulceration. All the children who presented with abscesses or lymphadenopathy following B.C.G. had had the vaccination done in Australia before going to Malaysia.

In previous years post B.C.G. abscesses had been noted but the association with Australian children, although present, had not been appreciated (Brown 1970).

\section{Case reports}

Twenty cases of post B.C.G. abscesses were studied. They were all Australians and their ages ranged from 4 months to 19 years with 18 of them being under 5 years (Table I).

They had been vaccinated in Sydney, Brisbane or Melbourne, either at Army or Civilian hospitals. The vaccinations had been performed by nursing sisters, doctors or medical assistants. The sites of the abscesses are shown in Table II.

Table I

Age range of 20 cases of post B.C.G. abscesses

\begin{tabular}{c|c|c|c|c}
\hline Under 1 year & 1 to 2 years & 2 to 5 years & 5 to 10 years & 10 to 20 years \\
\hline 4 & 6 & 8 & 1 & 1 \\
\hline
\end{tabular}

Table II

Sites of post B.C.G. abscesses in 20 cases

\begin{tabular}{l|c|l|c}
\hline \multicolumn{1}{c|}{ Site } & Cases & \multicolumn{1}{|c|}{ Site } & Cases \\
\hline $\begin{array}{l}\text { Rigltt axilla } \\
\text { Left axilla } \\
\text { Right pectoral }\end{array}$ & 10 & $\begin{array}{l}\text { Right supraclavicular } \\
\text { Right deltoid } \\
\text { Left deltoid }\end{array}$ & 1 \\
& 2 & 1 \\
\hline
\end{tabular}

* Now C.M.P. ANZUK Military Hospital, Singapore. 
Six cases occurred in late 1967 and 1968 and it was recognised that when the battalion was replaced by another from Australia there would be a fresh crop of cases from the newly arrived children who had been vaccinated in Australia prior to their journey to Malaysia.

In fact 14 new cases were seen out of about 300 children at risk, an incidence of approximately 45 per thousand. These cases were those children who had developed a lump or an abscess usually in the axilla of the B.C.G. vaccinated arm (Fig. 1), and which

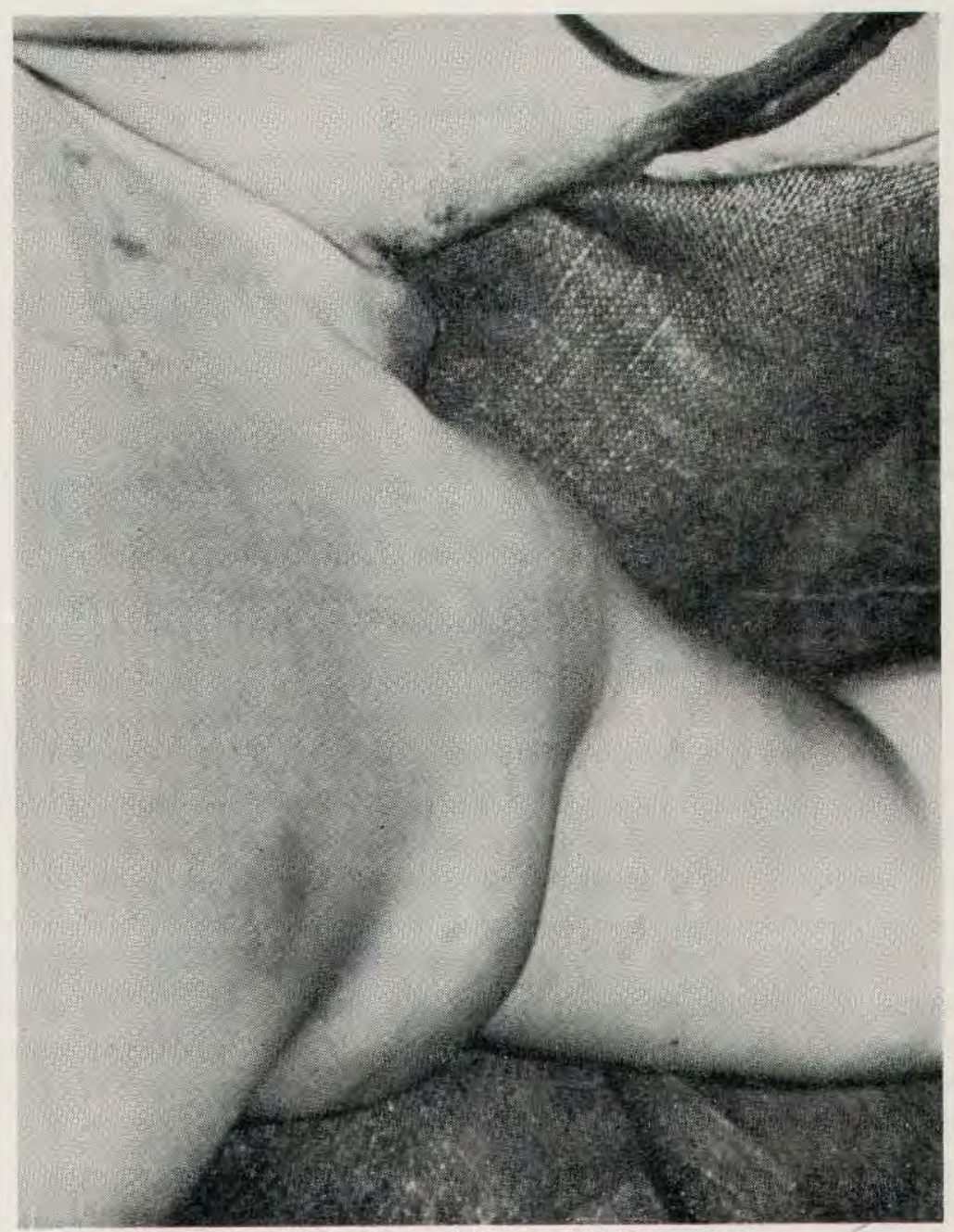

Fig. 1. Axillary abscess following B.C.G. vaccination.

had failed to respond to broad spectrum antibiotics, had not settled after 2 months and in many cases had been treated by Isoniazid (I.N.A.H.).

All the abscesses were incised under general anaesthesia, thoroughly curretted and the specimens sent for histology, direct smear stained with Ziel-Nielson (Z-N) and 
cultured for acid fast bacilli. There were 13 reports available, in 7 the cultures on Loewenstein-Jensen medium were positive for acid fast bacilli, in 3 the direct smear with Z-N stain was positive, and in 5 the histological picture showed a chronic granuloma with histiocytes, lymphocytes, epitheloid cells and giant cells of Langhans type consistent with a B.C.G. lupoid reaction.

Two cultures were sent to the Royal Army Medical College, Millbank, London for positive identification. The report stated that the cultures were of Mycotuberculosis bovis. Pathogenicity and sensitivity patterns suggested that they were strains of B.C.G.

All the patients with abscesses were treated with para-aminosalicylic acid (P.A.S.) and isoniazid (I.N.A.H.) and all were cured.

\section{Discussion}

B.C.G. was first used as a measure against tuberculosis in 1922. Experience gained since then has shown that it is effective in reducing the incidence of the disease in a population at risk. The Medical Research Council (M.R.C.) trial $(1956,1959,1963)$ showed a reduced incidence in vaccinated Mantoux negative children of 0.37 per thousand per year compared with 1.94 per thousand in the unvaccinated. Springett and Sutherland (1970) showed up-to-date figures from the Birmingham area since 1953 indicating that the incidence of tuberculosis in vaccinated children was approxiametly 10 per cent of that for unvaccinated children.

Normally the wheal left by an intradermal injection of B.C.G. disappears in about half an hour. Two or three weeks later a small, red, indurated, slightly tender nodule forms but grows slowly over the following week. In most cases the nodule becomes a small, superficial abscess which ulcerated and then crusts over rapidly. Later this crust separates leaving a small scar. The process is usually complete about 12 weeks from the vaccination date and only the scar remains.

Complications of B.C.G. vaccination are described and include excessive local ulceration, deep abscesses at the vaccination site and enlarged local lymph nodes.

In the M.R.C. trial (1956) the effect of B.C.G. (State Serum Institute, Copenhagen) and vole bacillus (Wells 1937, 1946, 1957) vaccines in the prevention of tuberculosis was evaluated. In the 20,800 children there were 22 cases of lupus at the site of vaccination. This complication had been described by Wylie and others (1954) after vole vaccine. Histologically the lesion was a typical non-caseous tuberculoid granuloma.

Intradermal vole bacillus vaccination caused a high incidence of local ulcers and the technique was therefore changed to a multiple puncture one. This complication is, however, still the commonest and is best defined as the presence after 12 weeks of an ulcer which is more than $1 \mathrm{~cm}$ across (King 1966).

Deep abscesses occurred commonly in the earlier days of vaccination. It was more common with vole vaccine (Wells 1957). It is usually attributed to subcutaneous injection of the vaccine, Miller, Seal and Taylor (1963) reported incidence rates of 1.5 per cent in new born infants to 0.5 per cent in 1 to 2 years group of 1,429 children. The usual treatment is aspiration and the injection of $10 \mathrm{mg}$ Streptomycin into the abscess cavity (King 1966) or Isoniazid systemically.

Regional lymphadenitis or abscess formation away from the vaccination site is well documented but is currently regarded as an unusual complication. Rosenthal (1957) 
noted that the larger the dose and the younger the child the higher is the incidence of regional lymphadenitis. Hsing (1954) using $0.1 \mathrm{mg}$ B.C.G. found that 2 to 23 per cent of infants less than 2 years old had suppurating axillary lymph glands.

Gainsford and Griffiths (1954) using $0.0375 \mathrm{mg}$ in the new born found 3 per cent of adenitis without suppuration. Viskum and Munch-Jenson (1955) showed 5 per cent of children less than 5 years and 0.8 per cent of 5 to 7 year olds out of a total of 31,320 developed enlarged lymph nodes.

In the Copenhagen study (1955) $0.0375 \mathrm{mg}$ of vaccine gave 5 per cent of adenitis, whereas double dose gave 10 per cent and quadruple dose $(0.15 \mathrm{mg})$ gave 25 per cent. In the older child aged 7 to 14 years, Edwards, Palmer and Magnus (1953) showed that 0.2 per cent got adenitis when the standard dose was used whereas 2.1 per cent did so when 4 times the dose was injected.

Miller, Seal and Taylor (1963) commented that the position of the abscess was related to the site of injection. When the vaccination was at the insertion of the deltoid the group of nodes in the anterior wall of the axilla is involved. With a high vaccination the cephalic nodes are involved, whereas with a shoulder tip site the bacilli reach the infra-clavicular nodes or those in the anterior triangle of the neck.

The incidence of these complications has been reduced by using a Dermo-jet injector. This has been proved effective and is widely used in British Schools (Bleasdale 1965, Wilson and Mikhail 1969) and has had a successful restricted trial in the Services (Power 1968).

There is increasing interest in the use of intradermal jet injection of live vaccines such as B.C.G. Live vaccines are not so dose dependant as killed vaccines, because the live vaccines produce their immunising effect as a result of multiplication in the tissues. The fact that not all the $0.1 \mathrm{ml}$ dose is implanted into the skin every time is not nearly so important as it is with primary vaccination using a killed vaccine. The freeze dried batches of B.C.G. (Glaxo) were shown by Springett and Sutherland (1970) to be equally effective in the prevention of tuberculosis as the liquid batches of the Copenhagen strain of B.C.G. This freeze dried vaccine is the one used by the Army. It was used in Terandak Hospital on children of all nationalities including Australians with no lasting complications recorded.

The blame for the post B.C.G. adenopathy and abscesses which occurred in Australian children vaccinated in Australia may lie with the vaccine used. This was B.C.G. vaccine prepared by the Commonwealth Serum Laboratory, Canberra.

In 1970, the Commonwealth Director of Tuberculosis collected figures for B.C.G. complications from 72,298 intradermal injections in Victoria, South Australia and Western Australia. Only three cases of axillary lymphadenopathy and one axillary abscess were recorded. (Howells 1971). The figures for 1968 and 1969 of complications occurring in Australia are not specifically recorded but were thought to be just as low.

Increased virulence of the vaccine as an explanation of the complications which occurred in vaccinated subjects going to Malaysia is therefore thought to be unlikely. Subcutaneous rather than intradermal injection is another possible cause of complications. However, the injections were given by a variety of Medical personnel, and in both civilian and military clinics so that no common injection factor can be directly. implicated. 
The only clue to have come from the enquiry in Australia was the comment that at one period of time National Service Trainees at Puckapunyal were producing a significant number of complications, and investigation revealed that they were receiving, on the same day and in the same arm, other immunising procedures such as T.A.B. and Tetanus Toxoid (Marshman 1972).

This possibility had been raised independently by the Director of Army. Health (Australia), following the report of 14 Australian servicemen's children in Singapore who had post B.C.G. complications. These children had received additional injections because they were going abroad, and this seems to be the only factor which was different from the Australian children who also received B.C.G. vaccination but who did not receive additional injections.

The Memorandum on Immunological Procedures of the Ministry of Defence (1968) sets down certain restrictions on the timing of B.C.G. vaccination.

1. The arm which has been vaccinated with B.C.G. should not normally be used for further vaccination for Three months, since such procedures may set up regional lymphadenitis.

2. B.C.G. vaccination should not be followed within Ten Days by killed vaccines or toxoids.

3. There should be an interval of at least Ten days between vaccination with B.C.G. and previous or later vaccination with all other live vaccines.

As a result of this investigation the Director-General of Medical Services (Australia) issued an administrative and medical technical instruction number 29 in August 72. This sets out the problem and lays down the time intervals to be observed between B.C.G. vaccination and other vaccinations. The details are very similar to the British system detailed earlier.

It is hoped that the problem of post B.C.G. abscesses in Australian service children moving to Singapore will thus be brought under control.

\section{Acknowledgements}

I should like to thank Major M. S. Owen-Smith, M.S., F.R.C.S., R.A.M.C. who did the surgical procedures. Also Dr. Gwyn Howells, First Assistant Director-General Department of Health, Canberra, Dr. R. S. A. Marsham, Director of Tuberculosis, Department of Health, Melbourne, Dr. E. W. Abrahams, Director of Tuberculosis, Department of Health, Brisbane, and Colonel R. H. Meyer, Director of Australian Army Health, all of whom co-operated in the investigation of the cause of these abscesses.

\section{REFERENCES}

Bleasdale, H. N. (1965). Tubercle (Edinb.) 46, 417.

BROWN, M. (1970). Personal communication.

EDWards, L. B. Palmer, C. E. and Magnus, K. (1953). Wld. Hlth. Org. Monogr. Ser. No. 12.

GAINSFORD, W. and GRIFFITHS, M. I. (1954). Tubercule (Edinb.) 35, 7.

Guld, J., Magnus, K., Tolderlurd, K., Biering-Sorenson, K. and Edwards, P. Q. (1955). Brit. med. J. ii, 1048 .

HowELLS, G. (1971). Personal communication.

HowelLs, G. (1972). Personal communication.

Hsing, C. T. (1954). Bull. Wld Hlth Org. 11, 1023.

KING, M. (1966). Medical Care in Developing Countries. Sections 17, 18 and 19. Oxford University Press. Nairobi. 
Marshman, R. S. A. (1972). Personal communication.

Medical Research Council (1956). Brit. med.J. i, 413.

MEDICAL ReSEARCH CounCIL (1959). Brit. med. J. ii, 379.

Medical ReSEARCH CounCIL (1963). Brit. med.J. i, 973.

Memorandum on ImMunological Procedures (1968). Ministry of Defence. H.M.S.O. London.

Miller, F. J. W., SeAL, R. M. E. and TAYLOR, M. D. (1963). Tuberculosis in Children. P. 143. J. \& A. Churchill. London.

Power, J. G. P. (1968). J, roy. Army med. Cps. 114, 98.

Rosenthal, S. R. (1957). B.C.G. Vaccination Against Tuberculosis. Little, Brown \& Co. Boston \& Toronto.

SPRINGETT, $V_{.}$H. and SUTHERLAND, I. (1970). Brit. med. J. 4, 148.

VISKUM, P. and MUNCH-JENSON, C. (1955). Acta tuberc. scand. 31, 320.

WeLLS, A. Q. (1937). Lancet i, 1221 .

Wells, A. Q. (1946). Spec. Rep. Ser. med. Res. Coun. (Lond.) No. 259.

WELLS, A. Q. (1957). Bibl. tuberc. (Basel), 8, 61 .

Wilson, M. B., and Mikhail, J. R. (1969). Brit. J. Dis. Chest. 63, 51.

WyLIE, J. A. R., BenNeTt, D. H. and Swithinbank, J. (1954). Thorax 9, 190.

\section{Sir Stanford Cade}

It is with regret that we note the death of Sir Stanford Cade who was for many years a member of the staff of the Westminster Hospital and Consultant in RadioTherapeutics to the Army.

Thanks to the close proximity of the Westminster to The Queen Alexandra Military Hospital and to the skill and kindness of Sir Stanford a close association between the two hospitals was quickly established and this surely is the most genuine and sincere memorial to one who gave so generously of his time and skill not only to thousands of our patients but also to our own officers with whom he shared his knowledge and expertise.

To his family we extend our most sincere sympathy. 